\title{
Otofaciocervical syndrome
}

INSERM

\section{Source}

INSERM. (1999). Orphanet: an online rare disease and orphan drug data base.

Otofaciocervical syndrome. ORPHA:2792

Otofaciocervical syndrome is a rare, genetic developmental defect during embryogenesis syndrome characterized by distinct facial features (long triangular face, broad forehead, narrow nose and mandible, high arched palate), prominent, dysmorphic ears (low-set and cup-shaped with large conchae and hypoplastic tragus, antitragus and lobe), long neck, preauricular and/or branchial fistulas and/or cysts, hypoplastic cervical muscles with sloping shoulders and clavicles, winged, low, and laterally-set scapulae, hearing impairment and mild intellectual deficit. Vertebral defects and short stature may also be associated. 